\title{
APPLICATION OF DIGITAL SURVEY MAPPING TECHNOLOGY IN THE INVESTIGATION OF COLORED WOOD STATUE IN THE CAOXI TEMPLE
}

\author{
Li Yumin $^{\mathrm{a}}$, Zheng Yu \\ ${ }^{a}$ Beijing Guo WenYan Information Technology co., LTD, Beijing, China \\ Commission ii . Digitizing heritage places
}

KEY WORDS: the CaoXi temple, colored wood statues, digital survey mapping technology

\begin{abstract}
:
The colored wood statues in the CaoXi Temple represent the Sandashi(Manjushri, Samantabhadra , Avalokitesvar) in the Buddhism. These statues with great value were carved in Dali kingdom of the Song dynasty. Because of natural and man-made reasons, disease has become very seriously both in the painted layer on the surface and the structure inside. So it is very important to record the current situation, analyze the structure, craft and material, and detect the cause of disease. This paper takes the colored wood statues as the research object, and kinds of digital survey technology were applied in the process. The Research results will play an important role in the protection, explanation and display.
\end{abstract}

\section{PROFILES OF THE CAO XI TEMPLE}

\subsection{General Instructions}

The Cao xi temple which was built in the tang dynasty is located in Anning of Yunnan province. The temple was built on the hill, sitting west to east. There are shanmen, tianwangdian, main shrine, houdian located in the central axis. the three famous color wood statues " Manjushri, Samantabhadra , Avalokitesvar " which were sculptured in the Song dynasty conserved in the main shrine, e.g. Figure 1. These three color wood statues with great values in history, art and science is one of the most precious cultural relics to the temple.

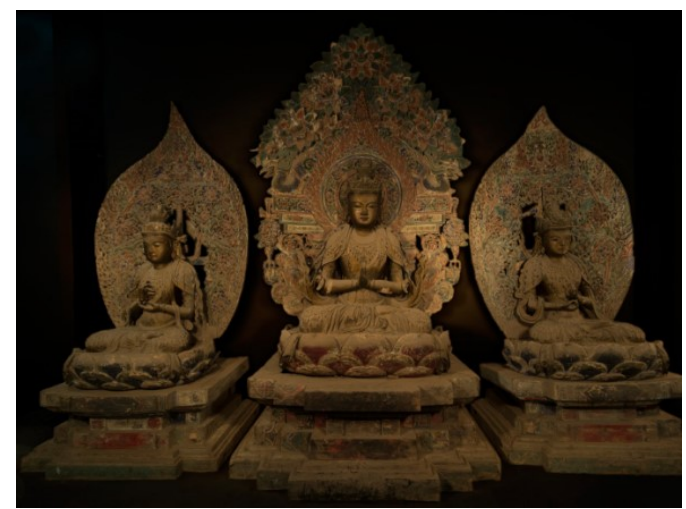

Figure 1. Color wood statues in the Caoxi Temple

In this paper, much data information of form, quality, color of the three color wood statues was obtained precisely by many survey and mapping methods.

\section{INFORMATION OBTAINING}

\subsection{Information Obtaining}

The three-dimensional scanning technique is used to record the geometry relationship between the statues, the statues and the building. The measuring error of the single point obtained is less than $2 \mathrm{~mm}$, and the data registration error is less than $3 \mathrm{~mm}$, e.g. Figure 2. After data processing, the distance of the point cloud of yard space is between $5 \sim 10 \mathrm{~mm}$, and the distance of the point cloud of the inside of the main shrine is between $1.5 \sim 3 \mathrm{~mm}$, e.g. Figure 3 .

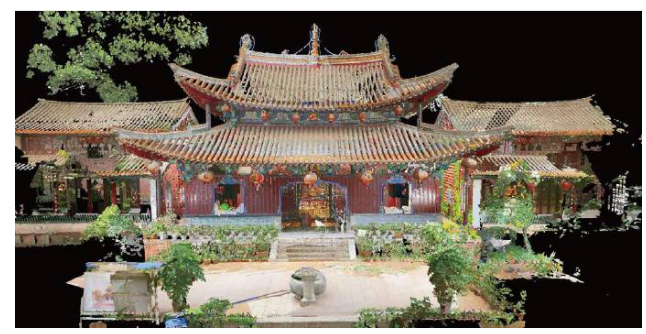

Figure 2. Point cloud of the yard

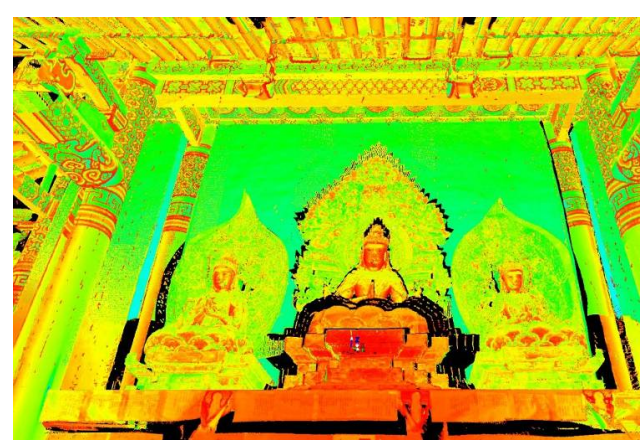

Figure 3. Point cloud of the building 
More accurate instrument for data obtaining is used to record the details of the tiny geometry and disease information of the color wood statues. This can be used for monitoring of development of extend of the disease. The measuring error of the single point obtained is less than $0.1 \mathrm{~mm}$, and the distance of the points in point cloud is less than $0.3 \mathrm{~mm}$, e.g. Figure 4 .

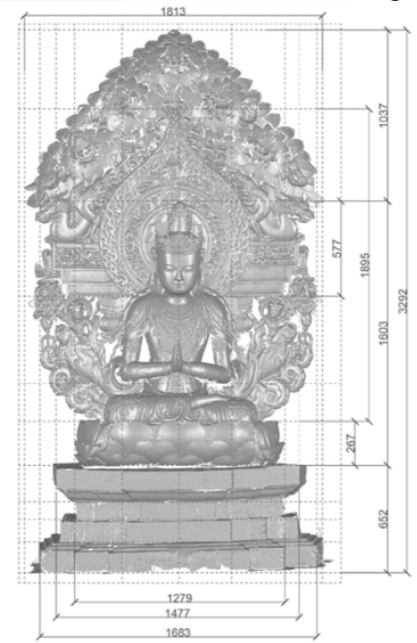

Figure 4. 3D modal of the statue

\subsection{Color and Texture Recording}

Recording the color and texture of the status objectively and actually. Color and texture of the high resolution images reflects the surface disease information, so resolution of the image obtained must be higher than 75DPI. Through these image, disease on the surface can be precisely located, e.g. Figure 5 .
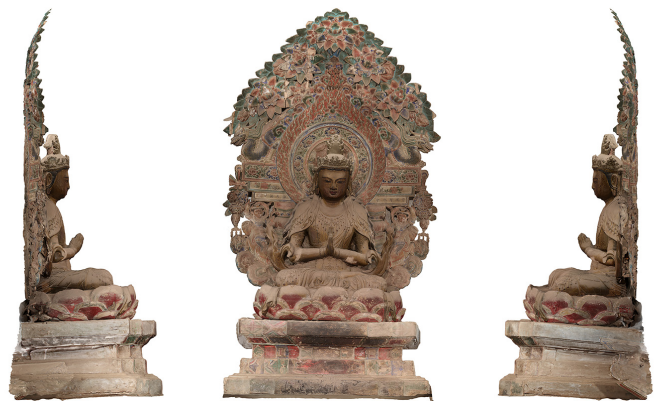

Figure 5. High resolution images of color and texture

\subsection{Colored Level Analysis}

SEM-EDS analysis, Raman spectrum analysis, XRF, XRD were used for obtaining the information on structures, the materials and the traditional crafts of the colored level of wood statues.

\subsection{Support Analysis}

Through the X-ray technology, the structure of the wood statues inside can be detected non-destructively. And furthermore, the repair marks in the history, the traditional crafts, and the cracks inside of the wood statues can also be found in the photos.

\section{SURVEY AND ANALYSIS OF WOOD STATUES}

\subsection{Analysis of Speculation of History}

There is a space for storage inside the chest of each wood statue through X-ray images, e.g. Figure 6. generally speaking, there should be sutras, jewels and the five cereals. However, These fillers don not exist anymore. This is probably related to the history of the temple's early neglected. We can also find some components which were made of clay through X-ray images, such as hands, wrists and forearms, e.g. Figure 7. This is probably the method of the beginning of the process, and it is more likely to be reshaped later, but the exact date of the repair is uncertain.

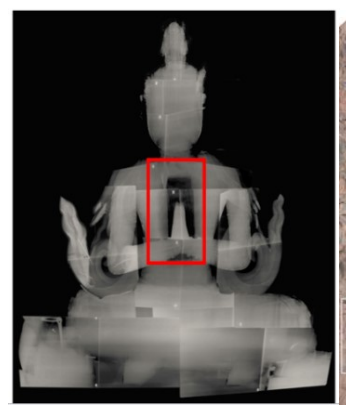

Figure 6. Space in the chest

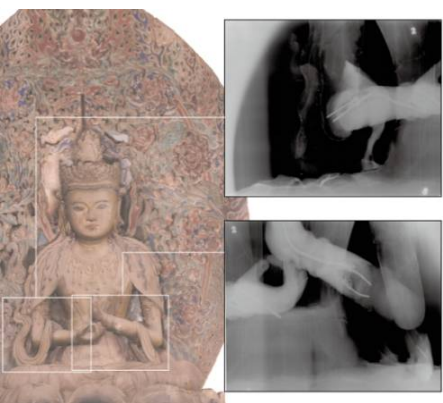

Figure 7. Components of different materials
Through analysis of colored level, 2-4 layers are found on the surface of the wood statues, e.g. Figure 8 . This shows that there have been at least four major repair or decoration in history.

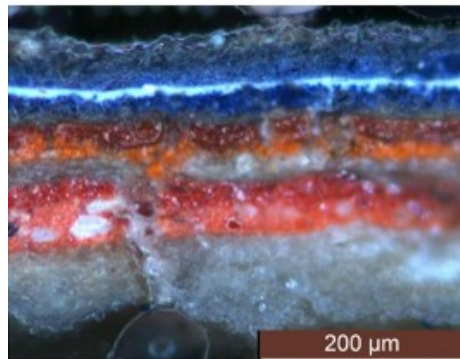

Figure 8. 4 layers color level

\subsection{Analysis of Material, Structure and Crafts}

\subsubsection{Analysis of the Support}

1. analysis of structure

The three wood statues have the same structure, and each of them is made up of four parts from bottom to top: the xumizuo, the wooden lotus, the main body and the back screen, e.g. Figure 9. The xumizuo which is made up of pieces of wood has four layers, and these layers are connected together by the mortise and tenon joints structure. The wooden lotus is on the top of xumizuo. The main body is on the top of the wooden lotus. The back screen is connected with the wooden lotus, and it is is fixed by 3 horizontal pieces of wood from the backside of the back screen , e.g. Figure 10. 


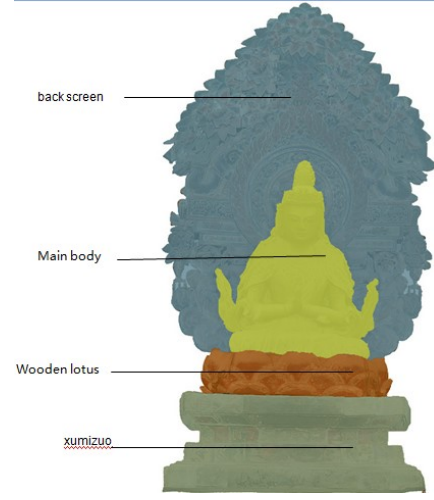

Figure 9. Structure of the statues

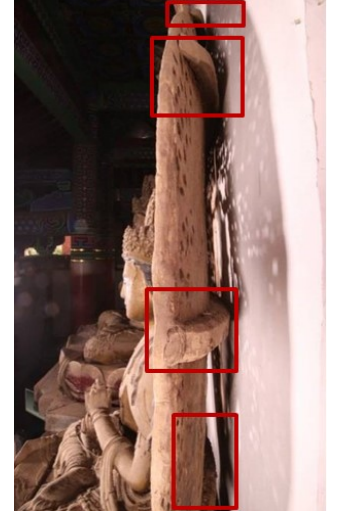

Figure 10. Horizontal pieces of wood from the backside of the back screen
The wood grain in the head and the body of each sculpture is coherent from the X-ray images, e.g. Figure 11. This means the head and torso are carved from a whole piece of wood. The torso is fixed on the wooden lotus by the mortise and tenon joints structure and the steel Joint Connector. And the headwear and ribbon which are carved separately are fixed on the main body by the mortise and tenon joints structure and the steel Joint Connector. These inner information of wood statues can be seen clearly from the X-ray images.

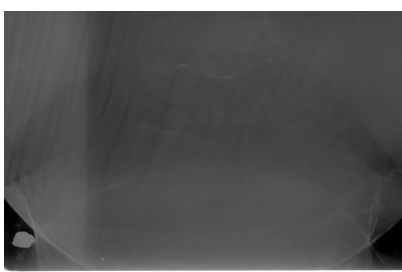

Figure 11. Wood grain of the statues

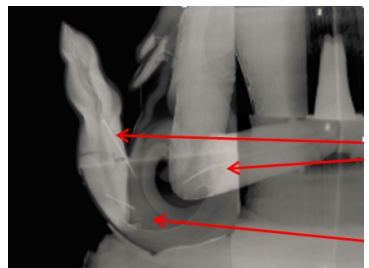

Figure 12. Steel Joint Connectors
The components ,such as hands, wrists, forearms, most of the headwear and ribbon, were made of clay through X-ray images. The steel Joint Connectors include not only traditional iron nails, but also modern iron nails. This shows that the three wood statues have been repaired many times, not only in history, but also in modern times, e.g. Figure 12.

\section{2. analysis of structure}

The preservation of the wood statue is influenced by its own material and its water content. Through field sampling and laboratory analysis, the name of lumber was determined by comparing with the library of materials by observing the morphology and arrangement of cells under the light microscope.

There is a difference in the type of wood used in parts of wood statue. The experimental result shows that, xumizuo of the sculpture of Samantabhadra is made of hardwood pine, but the ribbon of the sculpture of Bodhisattva is made of elm. From observing on the spot, except for that xumizuo, all the other materials should be elm, e.g. Figure 13.
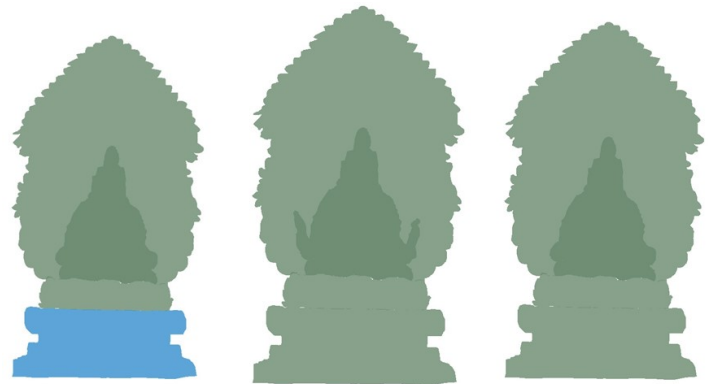

Figure 13. Material of lumber

The moisture content of the wood determines the expansion or contraction of the wood, e.g. Table 1. The moisture content of the xumizuo is between $11 \% \sim 15 \%$. This value is consistent with the average moisture content (annual mean value: $13.5 \%$, moisture content range: $9.8 \% \sim 16.6 \%$ ) of the Kunming area. It shows that these wood statues which have been put for many years have been consistent with the local wood equilibrium moisture content. They are already basically stable. However, because of the hydroscopicity, the moisture content of wood will change with the change of temperature and humidity in the environment. And the wood will be swell-shrinking further.

\begin{tabular}{|l|c|c|c|}
\hline $\begin{array}{l}\text { Detected } \\
\text { position }\end{array}$ & \multicolumn{3}{|c|}{ The moisture content } \\
\hline $\begin{array}{l}\text { The } \\
\text { xumizuo })\end{array}$ & $\begin{array}{l}\text { statue of } \\
\text { Samantabhadra }\end{array}$ & $\begin{array}{l}\text { statue of } \\
\text { Avalokitesvar }\end{array}$ & $\begin{array}{l}\text { statue of } \\
\text { Manjusri }\end{array}$ \\
\hline $\begin{array}{l}\text { The first } \\
\text { layer }\end{array}$ & 13.0 & 15.6 & 13.0 \\
$\begin{array}{l}\text { The second } \\
\text { laye }\end{array}$ & 13.1 & 13.4 & 13.2 \\
$\begin{array}{l}\text { The third } \\
\text { layer }\end{array}$ & 11.7 & 13.3 & 12.1 \\
$\begin{array}{l}\text { The forth } \\
\text { layer }\end{array}$ & 13.3 & 13.5 & 12.0 \\
\hline
\end{tabular}

Table 1. The moisture content of the xumizuo

\section{ANALYSIS OF DISEASE}

After hundreds of years of natural aging and long-term preservation in the semi-open environment, there are many kinds of diseases in these three wood statues. those diseases can be divided into support disease and color level disease.

\subsection{Disease of the Support}

The disease the support affects the stability and preservation of the structure of the statue seriously. There are several diseases of the statues: deterioration, slope, cracking and incompleteness. 

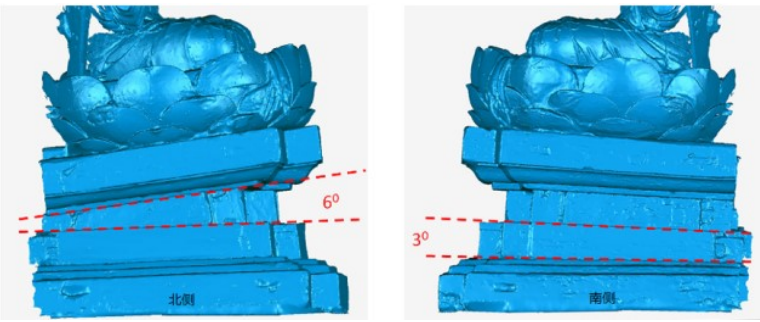

Figure 14. Angle of the slope

From outward appearance of the sculpture of Samantabhadra, it leans to the north. Measurements were made based on the threedimensional model. The sculpture is tilted backwards $6^{\circ}$ and

$3^{\circ}$ from the north and the south respectively, e.g. Figure 14 . And inclines to west in an angle of 3, e.g. Figure 15. It is assumed that the sculpture xumizuo was splitting or rotten at the rear of the third floor of the north side and the second floor of the south side of the supporting members, and the north side is much worse.

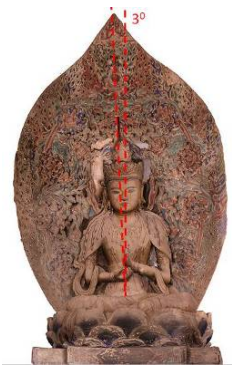

Figure15. The statue leans toward the

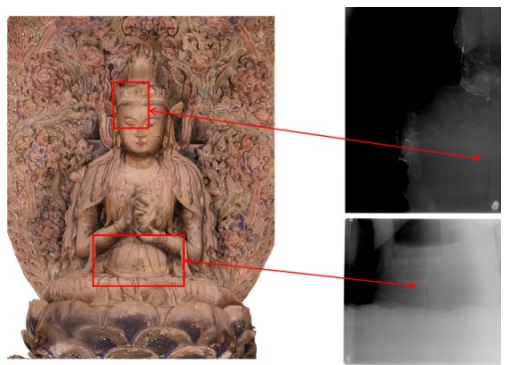

Figure 16. Crack in the statue north

Measurements were also made based on the three-dimensional model of the other two statues. They all lean to the west, but the the angle is very small.

Cracking is also one of the main diseases of the statues. This basically has two reasons: Aging of the fittings causes cracks in the joints of the components. Another reason is that swell-shrinking causes the wood to crack. A 0.7 meters long connected crack from head to abdomen is found inside of the statue of Samantabhadra through the X-ray images, e.g. Figure 16.

\subsection{Disease of the Color level}

The disease of color level affects the stability and preservation of the color level of the statue. There are several diseases of these statues: become warped, cracking, shedding, dust, and so on. According to the statistics, the area of the dust disease is the largest. This area covers $68.11 \%$ of the superficial area. Color lever layer warped and shedding become the most important and serious, covering $2.57 \%$ and $19.77 \%$ of the superficial area.

\section{CONCLUSION}

Based on the related documents and on the basis of field reconnaissance, this paper uses a variety of digital survey and mapping technology, extracts the cultural relic information objectively and accurately, and gets important information applied in the conservation projects for wood statues of Cao $\mathrm{Xi}$ temple. At the same time, exploring the operational and technical standards. This result will provide the operating process and technical standard for other projects in digtal investigation and mapping of ancient statues.

\section{REFERENCES}

Bai Chengjun, Wang Qiheng., 2013. 3d laser scanning technology is used in cultural relics and archaeological mapping. science and technology archaeology. pp. 436-439.

Ding Zhongming, Wu Laiming., 2013. The application of X-ray photographic technology in the study of cultural relics. Cultural preservation and archaeological science. pp. 38-46.

Hang Jianrong., 2012. The Cao Xi Temple records.

Jin Xi, He Shengtan., 1739. Anning state records.

Ma Erni, Zhao Guangjie., 2006. The dry condensation of the wood is from the equilibrium state to the non-equilibrium state. Journal of Beijing Forestry University. pp. 138-138.

Zhao Kun, Yang Dayu., 2013. The architectural style of cao xi temple and its religious culture. Arts Circle. pp. 93. 